\title{
HUMMINGBIRD RECOVERS FROM THE COLD
}

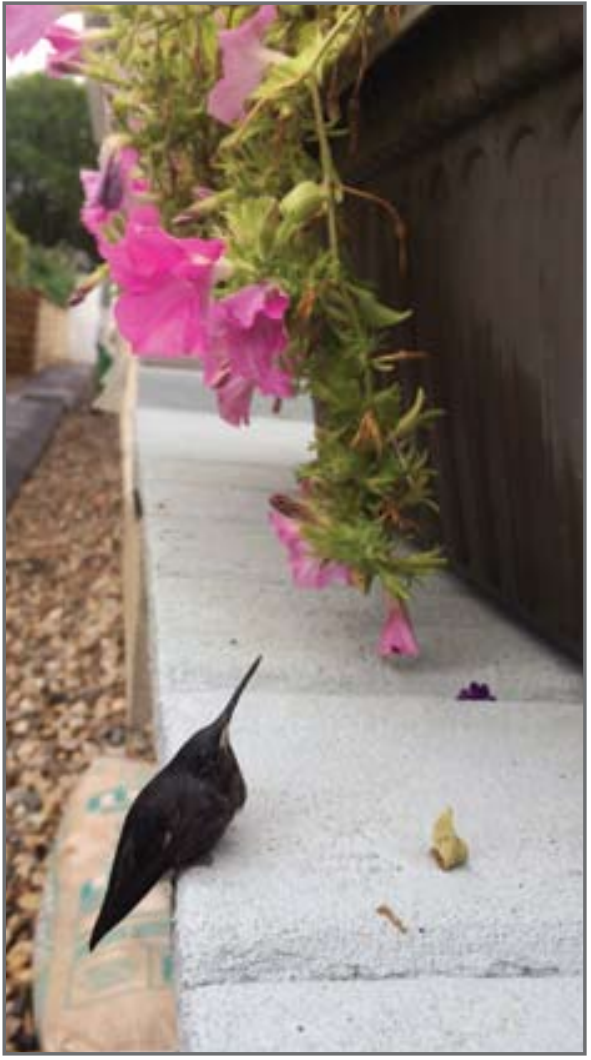

On the morning of September 7, 2016, Trevor Anderson stepped out on his front step and saw a sopping wet and cold hummingbird sitting motionless.

Trevor Anderson and Kaila MacDonald 922 Broder Street, Regina, SK S4N 3P6

\section{Margaret Anderson}

920 Broder Street, Regina, SK S4N 3P6

After a particularly cold September rainstorm, Trevor stepped out on his front step and saw a sopping wet and cold hummingbird sitting motionless on the step. It was the morning of September 7, 2016. The tiny bird had its eyes closed and its feathers were a deep black colour. The normal shimmering green coat of the Rubythroated Hummingbird (Archilochus colubris) was not there.

Trevor quickly brought his partner Kaila and his mother Margaret on to the scene and the three of us went to work to help this feathered friend. We made a small open box and tucked some soft face cloths on the bottom

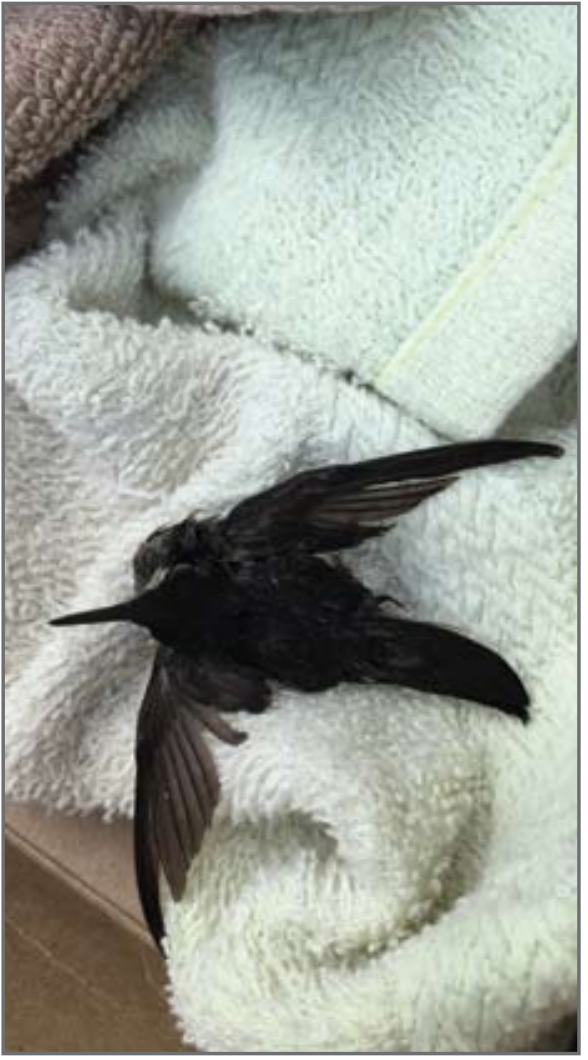

Trevor, Kaila and Margaret made a small open box and tucked some soft face cloths on the bottom of it to help dry and warm the hummingbird. Photo credits: Margaret Anderson

of it to help dry and warm the bird. Then we made the prescribed sugar water mixture that we use in our hummingbird feeders (one part white sugar to four parts water).

We then set about trying to feed the warm sugar water by dipping its bill in the cup of the sugar water. As this did not work too well, we then tried to feed it through a clean eye dropper. We filled the dropper and carefully held the end of the dropper near its bill squeezing a small drop of water out of the end of the dropper. To our delight the bird's tiny black tongue flicked into the dropper - it wanted to drink! As it lay in the box, its little wings were spread out on the cloths and, other than moving its beak to seek more water, it was not moving much.

We continued watching and feeding this bird for more than an

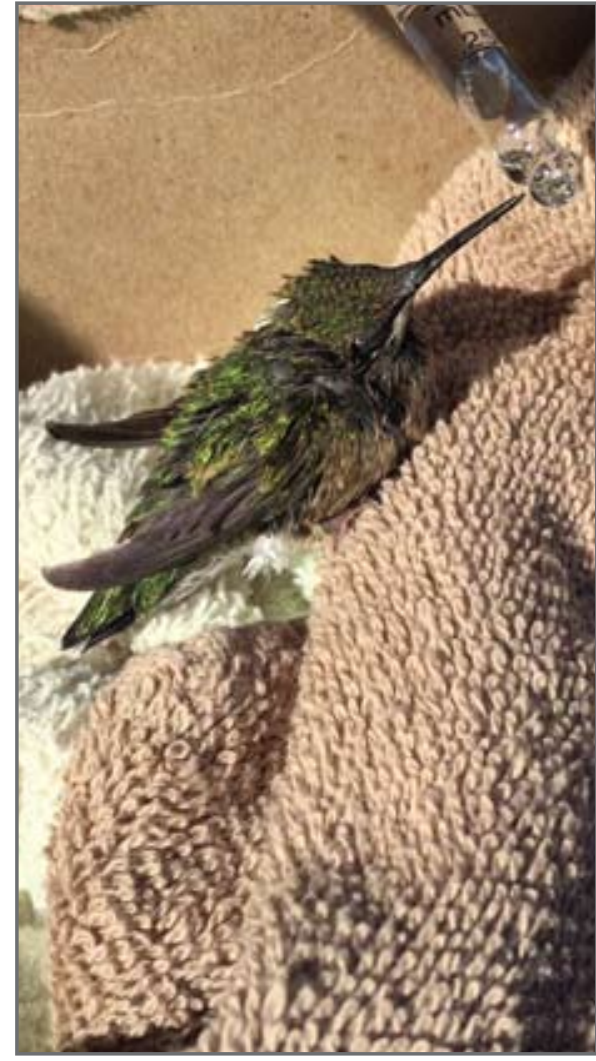

As the hummingbird drank the sugar water and started drying out, and as it regained its strength, its green colour first re-appeared on its back before showing up again on its head.

hour. As the hummingbird drank and started drying out, we saw an amazing thing. Its tail was the first part of its feathers that turned green and as it regained its strength, the green colour moved up its back and then on to its head. Then you could see our little friend start to ruffle its feathers and move its wings back to its sides. It was remarkable and so thrilling to see this transformation.

While watching this, the clouds broke up enough to provide some sunshine and added warmth for our friend. A few more minutes of drying in the sun enabled this beautiful young hummingbird to launch out of our rescue box up into our elm tree. It sat there for a few minutes and then flew off out of sight. We all hoped it would head south as soon as possible to avoid further cold Saskatchewan fall showers! 